\title{
Climate Change, Air Quality and Urban Health: Evidence from Urban Air Quality Surveillance System in 161 Cities of China 2014
}

\author{
Longjian Liu ${ }^{*}$, Xuan Yang1, Mingquan Wang2, Yong Long1,3, Heqing Shen4, Yan Nie ${ }^{1,5}$, \\ Liangxia Chen ${ }^{1,6}$, Haoyang Guo ${ }^{1}$, Feng Jia ${ }^{1}$, Julianne Nelson' ${ }^{1}$, Guangzi Song1, Arthur Frank ${ }^{7}$, \\ Seth Welles ${ }^{1}$, Charles N. Haas ${ }^{8}$
}

\begin{abstract}
${ }^{1}$ Department of Epidemiology and Biostatistics, Drexel University Dornsife School of Public Health, Philadelphia, USA
${ }^{2}$ Shanghai Advanced Research Institute, Chinese Academy of Sciences, Shanghai, China

${ }^{3}$ Department of Epidemiology, Fourth Military Medical University School of Public Health, Xi'an, China

${ }^{4}$ Institute of Urban Environment of Chinese Academy of Sciences (CAS), Xiamen, China

${ }^{5}$ School of Public Administration, Guizhou University, Guiyang, China

${ }^{6}$ Shandong Center for Disease Control and Prevention, Jinan, China

${ }^{7}$ Department of Environment \& Occupational Health, Drexel University Dornsife School of Public Health, Philadelphia, USA ${ }^{8}$ Department of Civil, Architectural, and Environmental Engineering, Drexel University College of Engineering, Philadelphia, USA

Email: *Longjian.liu@drexel.edu
\end{abstract}

How to cite this paper: Liu, L.J., Yang, X., Wang, M.Q., Long, Y., Shen, H.Q., Nie, Y., Chen, L.X., Guo, H.Y., Jia, F., Nelson, J., Song, G.Z., Frank, A., Welles, S. and Haas, C.N. (2018) Climate Change, Air Quality and Urban Health: Evidence from Urban Air Quality Surveillance System in 161 Cities of China 2014. Journal of Geoscience and Environment Protection, 6, 117-130. https://doi.org/10.4236/gep.2018.63011

Received: March 20, 2018

Accepted: April 5, 2018

Published: April 8, 2018

\begin{abstract}
Air pollution has posed a serious public health issue in China. In the study, we aimed to examine the burden of air pollution and its association with climate factors and total mortality. City-level daily air quality index (AQI) data in 161 cities of China in 2014, and meteorological factors, socioeconomic status and total morality were obtained from China environmental, meteorology and healthcare agencies. Linear regression, spatial autocorrelation analysis and panel fixed models were applied in data analysis. Among 161 cities, monthly average AQI was significantly different by seasons and regions. The highest average AQI was in winter, and the lowest in summer. A significant clustering distribution of AQI by cities was observed, with the highest AQI in north China $(22$ cities, mean $=117.36)$. Among the 161 cities, 5 cities $(3 \%)$ had AQI > 150 (e.g., moderate polluted reference value), and 50 cities (31.1\%) had AQI between 100 and 150 (slightly polluted value). Daily heat index, precipitation and sunshine hours were negatively and significantly, but air pressure was positively correlated with AQI. Cities with higher AQI concentrations had higher total mortality than those with lower AQI. This AQI-mortality associa-
\end{abstract}


tion remained significant after adjustment for socioeconomic status. In conclusion, the study highlights the burden and seasonal, regional and areas variations in air pollution across the nation. Air pollution is estimated to account for more than $4 \%$ of the urban health inequality in total mortality in China.

\section{Keywords}

Climate Change, Air Pollution, Urban Health, China

\section{Introduction}

Urban air pollution is becoming a global concern as it has great impacts on the environment and public health. With the rapid increase in urbanization and economy in China since the early 1980s [1], there has been a concomitant cost of worsening air quality. Outdoor air pollution has become a top environmental concern in China [2] [3] [4] [5], and has been examined by several studies [2] [3] [6]-[12]. However, few studies examined the association between climate change and air quality, and how this differs by physical and socioeconomic environments in China. In this study, we applied the most recently nationally representative data from multiple resources on air quality, meteorological factors and health outcomes (e.g. total mortality) that were collected and reported under the guidelines of the Ministry of Environmental Protection, China Meteorological Data Sharing Service System, and National Health Statistics Center of the People's Republic of China [13] [14] [15] [16]. We tested two hypotheses: 1) There are significant variations in air pollution concentrations by seasonal, geographic and socioeconomic regions in China. 2) Air pollution was positively correlated with total mortality rates.

\section{Methods}

\subsection{Design}

Data $(n=161$ cities $)$ from almost half of the total cities $(n=342)$ in China were analyzed ecologically and cross-sectionally using standard and robust analysis approaches.

\subsection{Exposures}

\subsubsection{Air Pollution Data}

In China, daily air pollution data are reported by the Chinese Ministry of Environmental Protection (MEP) [13]. Data on Air Pollution Index (AQI) in 2014 were analyzed for 161 major cities across the country. AQI is a sum indicator calculated from a group of air pollutants, which is derived from daily measurements of five atmospheric pollutants: particulate matter (PM10 and PM2.5), carbon monoxide $(\mathrm{CO})$, nitrogen dioxide $\left(\mathrm{NO}_{2}\right)$, sulfur dioxide $\left(\mathrm{SO}_{2}\right)$, and ozone $\left(\mathrm{O}_{3}\right)$. The average daily concentrations of pollutants in individual cities were computed using the centering method [17]. 


\subsubsection{Meteorology Data}

To analyze the correlation between daily AQI and daily climate change of $161 \mathrm{ci}-$ ties with daily AQI measures, we were able to collect and match 50 cities that had daily meteorology data available from the Chinese Meteorological Data Sharing Service System [14] [18]. In the present analysis, we included six major meteorological indicators: temperature, relative humidity, precipitation, sunshine hours, pressure and heat index (HI, estimated using the regression equation proposed by Lans Rothfusz [19]).

$$
\begin{aligned}
& \mathrm{HI}=-42.379+2.04901523^{\star} \mathrm{T}+10.14333127^{\star} \mathrm{RH}-0.22475541^{\star} \mathrm{T}^{\star} \mathrm{RH} \\
& -0.00683783^{\star} \mathrm{T}^{\star} \mathrm{T}-0.05481717^{\star} \mathrm{RH} H^{\star} \mathrm{RH}+0.00122874^{*} \mathrm{~T}^{\star} \mathrm{T}^{\star} \mathrm{RH}+ \\
& 0.00085282^{\star} \mathrm{T}^{\star} \mathrm{R} \mathrm{H}^{\star} \mathrm{RH}-0.00000199^{\star} \mathrm{T}^{\star} \mathrm{T}^{\star} \mathrm{RH} \mathrm{H}^{\star} \mathrm{RH}
\end{aligned}
$$

where $T$ is temperature in degrees $F$ and $R H$ is relative humidity in percent.

\subsubsection{Health Outcomes Data}

Data on annual average city-level mortality from all-cause in 2014 were collected from China Health Statistics and Statistical Communique of the People's Republic of China on National Economic and Social Development [15] [16].

\subsubsection{Covariates}

Number of total population and gross domestic product (GDP) in 2014 by cities were obtained from 2014 National Economic and Social Development Statistics Bulletin [15].

\subsection{Statistical Analysis}

In the first group of analyses, univariate analyses were used to describe the pattern of daily, weekly, seasonally and yearly AQI concentrations by city and regions. Seasons were classified as spring (March to May), summer (June to August), fall (September to November), and winter (December to February). Six regions are grouped: North China (Beijing, Tianjin, Hebei, Shanxi, and Inner Mongolia), Northeast China (Liaoning, Jilin, and Heilongjiang), East China (Shanghai, Jiangsu, Zhejiang, Anhui, Fujian, Jiangxi and Shandong), South Central China (Henan, Hubei, Hunan, Guangdong, Guangxi, Hainan, Hong Kong, and Macau), Southwest China (Chongqing, Sichuan, Guizhou, Yunnan, and Tibet), and Northwest China (Shannxi, Gansu, Qinghai, Ningxia, and Xinjiang) [20].

In the second group of analyses, spatial patterns of AQI and air pollutants were described using Arc Geographic Information System (Version 12, Redlands, CA) [21] and the correlation of AQI with heat index and spatial variations were examined using linear correlation and spatial autocorrelation analysis techniques. In Spatial autocorrelation, Moran's I statistics were calculated using SAS 9.3 Proc variogram [22]. Moran's I is a measure of spatial autocorrelation and it indicates how AQI values were measured on the basis of their location (point) that is identified by latitude and longitude of the surveillance station where air pollutants were measured. Let $Z$ (s) represent the value of $Z$ at point $s$. 
For locations $s$ and $s+h$, the variance of the difference of the $Z(s)$ and $Z(s+h)$ is of interest. Moran's $I$ is calculated based on cross-products of the deviations from the mean:

$$
I(h)=\frac{n}{N(h)} \frac{\sum_{i} \sum_{j} w_{i j}\left(Z\left(s_{i}\right)-\overline{Z(s)}\right)\left(Z\left(s_{j}\right)-\overline{Z(s)}\right)}{\sum_{i}\left(Z\left(s_{i}\right)-\overline{Z(s)}\right)^{2}}
$$

where $w_{i j}$ are the elements of the weight matrix, and $N(h)$ is the sum of the elements of the weight matrix.

Meanwhile, Geary's C statistic was calculated, an alternative method to measure spatial autocorrelation, estimated using the following formula [22].

$$
C(h)=\frac{n-1}{2 N(h)} \frac{\sum_{i} \sum_{j} w_{i j}\left(Z\left(s_{i}\right)-Z\left(s_{j}\right)\right)^{2}}{\sum_{i}\left(Z\left(s_{i}\right)-\overline{Z(s)}\right)^{2}}
$$

In the third group of analyses, correlations between AQI and climate factors were examined using linear correlation and regression analysis. Because of the nature of the spatial-based cross-sectional and time-series data, we further applied Panel (data) analysis methods [23] [24]. We performed an independently pooled model, and a fixed effect model, because time-specific effects on AQI are not randomly distributed in the data.

In the fourth group of analyses, the association between AQI and total mortality were examined using simple and partial (adjusted) correlation analysis methods. In the partial correlation analysis, we adjusted for city-level socioeconomic status (assessed by gross domestic product per capital).

All statistical analyses were conducted using SAS software, version 9.3 (SAS Institute, Cary, North Carolina) [22]. The level of significance was set at a 2 -sided test at $\mathrm{p} \leq 0.05$.

\section{Results}

\subsection{Characteristics of Study Sample}

Table 1 shows that of 161 cities the mean (SD) and medial AQI were 95.69 (37.21), and 89.28 (quartile range: 70.62 - 112.31), and of them mean temperature in 50 cities (climate data available and matched for 50 cities) was 14.34 $(11.00)^{\circ} \mathrm{C}$ in 2014 . The means (SD) of heat index, precipitation, sunshine hours and pressure are shown in Table 1 as well.

\subsection{Seasonal and Regional Trend of AQI in 2014}

Figure 1 depicts the six geographic regions in mainland China (on the left side), and the monthly average AQI concentrations by regions from January to December in 2014 (on the right side). All six regions had higher AQI in the winter term, followed by earlier spring (March and April), and alter fall (October and November), and the lowest AQI in the end of summer and the beginning of fall (August and September). Of the four seasons, the highest average concentrations 
Table 1. Annual average concentration of air indicators in 50- and 161 cities of China, 2014.

\begin{tabular}{|c|c|c|c|c|c|c|}
\hline & \multirow{2}{*}{$\begin{array}{c}\text { No. } \\
\text { Cities }^{\mathrm{b}}\end{array}$} & \multirow{2}{*}{ Mean } & \multirow{2}{*}{ (SD) } & \multirow{2}{*}{ Median } & \multicolumn{2}{|c|}{$\mathrm{IQR}^{\mathrm{a}}$} \\
\hline & & & & & $25 \%$ & $75 \%$ \\
\hline \multicolumn{7}{|l|}{ Air quality indicator } \\
\hline Air quality index (AQI) & 161 & 95.69 & $(37.21)$ & 89.28 & 70.62 & 112.31 \\
\hline \multicolumn{7}{|l|}{ Climate indicators } \\
\hline Temperature $\left({ }^{\circ} \mathrm{C}\right)$ & 50 & 14.34 & $(11.00)$ & 16.35 & 7.29 & 23.20 \\
\hline Heat index & 50 & 53.27 & $(21.71)$ & 57.31 & 39.37 & 70.86 \\
\hline Precipitation $(0.1 \mathrm{~mm})$ & 50 & 758.15 & $(949.37)$ & 439.00 & 94.00 & 1079.00 \\
\hline Sunshine hours (hrs) & 50 & 172.35 & $(69.54)$ & 177.65 & 120.15 & 221.90 \\
\hline Pressure $(\mathrm{kPa})$ & 50 & 97.82 & (5.33) & 99.91 & 97.35 & 100.87 \\
\hline
\end{tabular}

a: IQR: Interquartile range; b: Of 161 cities with AQI measures, 50 cities had daily climate change measures.
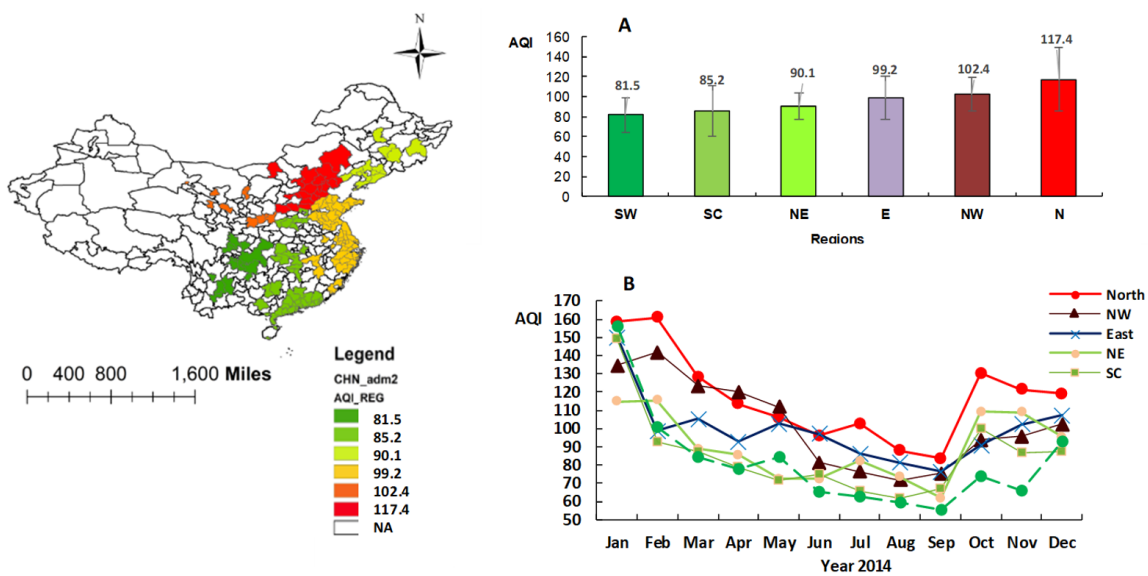

Figure 1. Annual air quality index (AQI) by regions (A) and by and regions (B) in China 2014.

$( \pm \mathrm{SD})$ of AQI were in winter $(119.58 \pm 2.19)$, followed by spring (95.02 \pm 1.35$)$, fall $(89.30 \pm 1.37)$, and summer $(78.86 \pm 1.05)$ in 2014 (Table 2). The ANOVA test shows that compared with summer as the baseline, there were significant difference between spring and summer $(\mathrm{p}<0.0001)$, fall and summer $(\mathrm{p}<0.0001)$, winter and summer $(\mathrm{p}<0.0001)$. Table 2 also shows that among 6 regions, the highest average concentrations $( \pm \mathrm{SD})$ of $\mathrm{AQI}$ were in north (117.36 \pm 2.73 ), followed by northwest $(102.39 \pm 2.79)$, east $(99.23 \pm 1.26)$, northeast (90.06 \pm 1.89$)$, south central $(85.18 \pm 1.66)$, southwest $(81.54 \pm 2.72)$.

\subsection{Spatial Patterns of AQI}

Figure 2 depicts a significant variation in five major air pollutants (PM2.5, PM10, CO, SO2, 1-Hour Ozone, and 8-Hour Ozone) across the country. Figure 3 depicts the annual AQI concentrations across the nation (on the right-side). Spatial autocorrelation analysis technique was further applied to test whether cities with higher AQI were clustered in certain areas. The result indicates that 
Table 2. Average AQI by season and region in 161 cities of China, 2014.

\begin{tabular}{|c|c|c|c|c|c|c|}
\hline & \multicolumn{4}{|c|}{ ANOVA test } & \multicolumn{2}{|c|}{ Rank test } \\
\hline & No. cities & Mean & (SE) & $\mathrm{p}$-value & Median & p-value \\
\hline \multicolumn{7}{|l|}{ Season } \\
\hline Spring (Mar, Apr, May) & 161 & 95.02 & $(1.35)$ & $<.0001$ & 91.67 & $<.0001$ \\
\hline Summer (Jun, Jul, Aug) & 161 & 78.86 & $(1.05)$ & ref & 75.93 & ref \\
\hline Fall (Sep, Oct, Nov) & 161 & 89.30 & $(1.37)$ & $<.0001$ & 84.16 & 0.003 \\
\hline Winter ( Dec, Jan, Feb) & 161 & 119.58 & $(2.19)$ & $<.0001$ & 108.57 & $<.0001$ \\
\hline \multicolumn{7}{|l|}{ Region } \\
\hline North & 22 & 117.36 & $(2.73)$ & $<.0001$ & 110.00 & $<.0001$ \\
\hline Northeast & 16 & 90.06 & $(1.89)$ & 0.021 & 87.16 & $<.0001$ \\
\hline East & 50 & 99.23 & $(1.26)$ & $<.0001$ & 93.71 & $<.0001$ \\
\hline South central & 43 & 85.18 & $(1.66)$ & 0.238 & 77.46 & 0.436 \\
\hline Southwest & 15 & 81.54 & $(2.72)$ & ref & 71.02 & ref \\
\hline Northwest & 15 & 102.39 & $(2.79)$ & $<.0001$ & 97.05 & $<.0001$ \\
\hline
\end{tabular}

*AN0VA: Analysis of Variance. Rank test used Mann-Whitney U test.
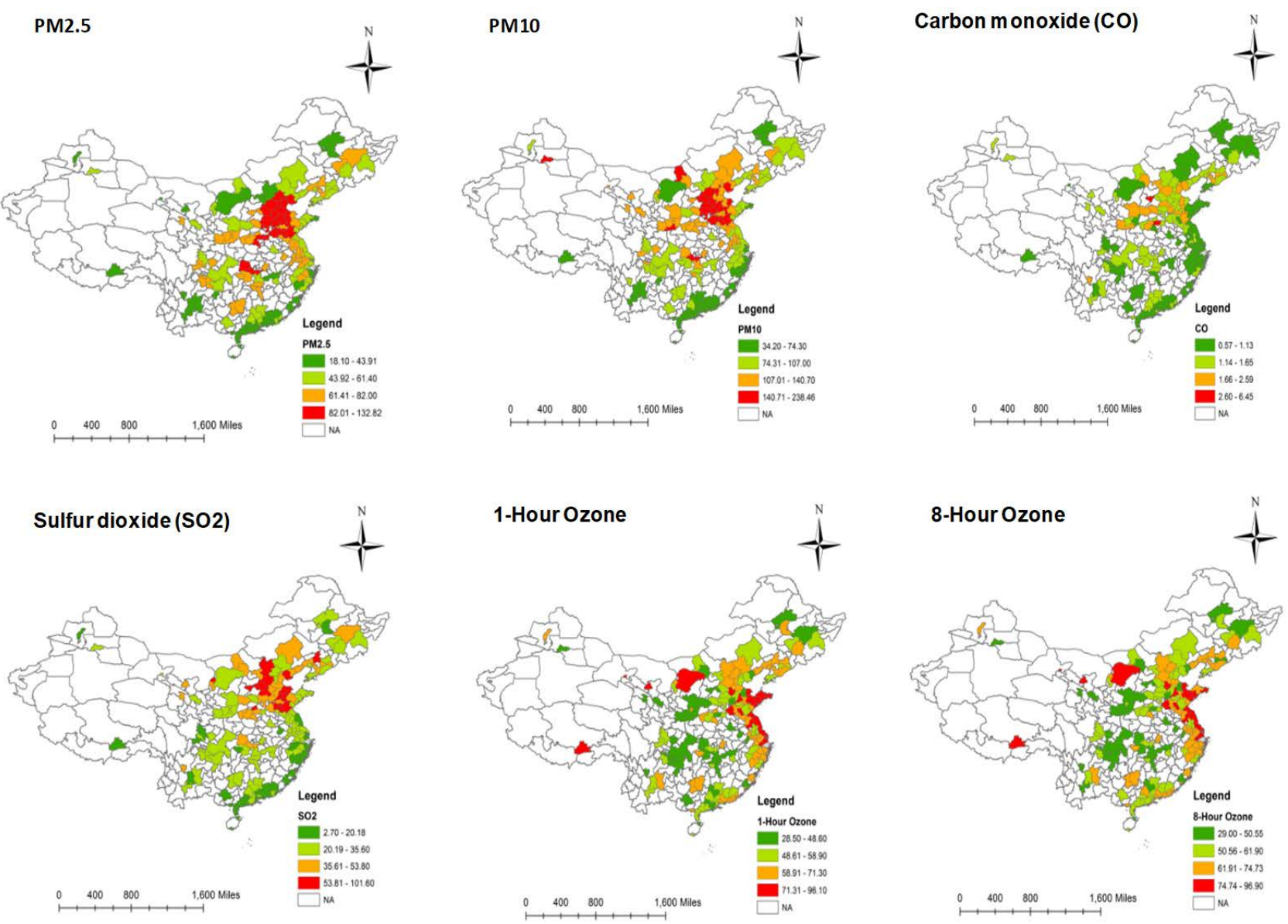

Figure 2. Annual mean levels of major pollutants in 161 cities of China 2014. 
Moran's I coefficient $(0.22)$ was greater than $0(\mathrm{p}<0.0001)$, and Geary's $\mathrm{C}$ coefficient $(0.80)$ was less than 1 ( $\mathrm{p}<0.0001)$. Both statistics indicate that the values of AQI measures across cities had positive spatial autocorrelation, meaning the spatial distribution of high AQI values were more spatially clustered rather than dispersed.

In 2014, Of 161 cities, more than one third (37.27\% - 39.75\%) had AQI 100-149, and 67 cities (41.61\%) had AQI 150 and higher in January (Table 3).

\subsection{Correlation between AQI and Meteorological Factors}

Of the 161 cities with AQI measures, 50 cities had available data for meteorological measures. Among these cities, simple correlation analysis indicated that monthly average AQI concentrations were significantly and negatively correlated with temperature, heat index, precipitation, and sunshine hours, but significantly and positively associated with pressure (Table 4).

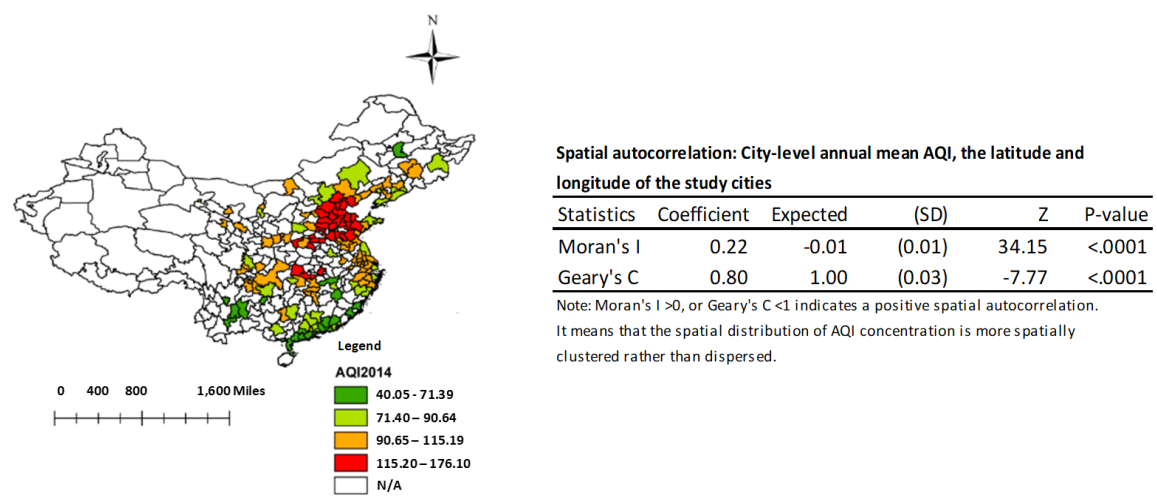

Figure 3. Special autocorrelation analysis: City-level annual AQI.

Table 3. Number and percentages of cities with mean AQI by different criteria from January to December ${ }^{\mathrm{a}}$.

\begin{tabular}{|c|c|c|c|c|c|c|c|c|c|c|c|c|}
\hline & Jan & Feb & Mar & Apr & May & Jun & Jul & Aug & Sep & Oct & Nov & Dec \\
\hline \multicolumn{13}{|l|}{ Excellent } \\
\hline No. cities & 0 & 4 & 3 & 3 & 14 & 12 & 18 & 18 & 14 & 0 & 3 & 1 \\
\hline$\%$ & 0 & 2.48 & 1.86 & 1.86 & 8.7 & 7.45 & 11.18 & 11.18 & 8.7 & 0 & 1.86 & 0.62 \\
\hline \multicolumn{13}{|l|}{ Good } \\
\hline No. cities & 34 & 70 & 86 & 110 & 83 & 106 & 117 & 125 & 134 & 98 & 94 & 85 \\
\hline$\%$ & 21.12 & 43.48 & 53.42 & 68.32 & 51.55 & 65.84 & 72.67 & 77.64 & 83.23 & 60.87 & 58.39 & 52.8 \\
\hline \multicolumn{13}{|c|}{ Light polluted } \\
\hline No. cities & 60 & 61 & 62 & 43 & 63 & 43 & 26 & 18 & 13 & 54 & 52 & 64 \\
\hline$\%$ & 37.27 & 37.89 & 38.51 & 26.71 & 39.13 & 26.71 & 16.15 & 11.18 & 8.07 & 33.54 & 32.3 & 39.75 \\
\hline \multicolumn{13}{|c|}{ Moderately polluted } \\
\hline No. cities & 67 & 26 & 10 & 5 & 1 & 0 & 0 & 0 & 0 & 9 & 12 & 11 \\
\hline$\%$ & 41.61 & 16.15 & 6.21 & 3.11 & 0.62 & 0 & 0 & 0 & 0 & 5.59 & 7.45 & 6.83 \\
\hline
\end{tabular}

a: Air quality level: Excellent: AQI < 50; Good: AQI $\geq 50$ and AQO < 100; Light polluted: AQI $\geq 100$ and AQI < 150; Moderately polluted: AQI $\geq 150$. 
Similar correlation relationships between QAI and meteorological factors were observed using panel pooled analysis. It indicates that $28.8 \%$ (R2) of the variations in AQI could be explained by the differences in meteorological factors (Table 5). As AQI varies by time, using panel fixed time (month) effect models, the results suggest that $39.2 \%$ of the variation in AQI could be explained by the differences in meteorological factors and time (months) in China 2014.

Table 4. Correlation between monthly average AQI and climate indicators in 2014.

\begin{tabular}{ccccccc}
\hline & Number of cities & & \multicolumn{2}{c}{ Pearson } & & \multicolumn{2}{c}{ Spearman } \\
\cline { 3 - 6 } & & $\mathrm{r}$ & $\mathrm{p}$-value & $\mathrm{r}$ & $\mathrm{p}$-value \\
\hline Temperature $\left({ }^{\circ} \mathrm{C}\right)$ & 50 & -0.44 & $<0.0001$ & -0.50 & $<0.0001$ \\
Heat index & 50 & -0.44 & $<0.0001$ & -0.50 & $<0.0001$ \\
Precipitation $(0.1 \mathrm{~mm})$ & 50 & -0.39 & $<0.0001$ & -0.47 & $<0.0001$ \\
Sunshine hours $(\mathrm{hrs})$ & 50 & -0.16 & 0.000 & -0.11 & 0.009 \\
Pressure $(\mathrm{kPa})$ & 50 & 0.13 & 0.001 & 0.18 & $<0.0001$ \\
\hline
\end{tabular}

Table 5. Panel analysis of the associations between daily AQI and climate factors.

\begin{tabular}{|c|c|c|c|c|c|c|c|c|}
\hline & \multicolumn{8}{|c|}{ Pooled Model } \\
\hline & 1 & & 2 & & 3 & & 4 & \\
\hline & Beta $^{a}$ & $p$ & Beta & $p$ & Beta & $p$ & Beta & $p$ \\
\hline \multicolumn{9}{|l|}{ Year 2014} \\
\hline \multicolumn{9}{|l|}{ Sample size (n) } \\
\hline Heat Index & -0.720 & $<0.0001$ & -0.534 & $<0.0001$ & -0.434 & $<.0001$ & -0.485 & $<.0001$ \\
\hline Precipitation $(0.1 \mathrm{~mm})$ & & & -0.008 & $<0.0001$ & -0.011 & $<0.0001$ & -0.011 & $<.0001$ \\
\hline Sunshine hours (hrs) & & & & & -0.115 & $<0.0001$ & -0.086 & $<.0001$ \\
\hline Pressure $(\mathrm{kPa})$ & & & & & & & 0.926 & 0.0007 \\
\hline Fixed time effect (Month) & $\mathrm{N}$ & & $\mathrm{N}$ & & $\mathrm{N}$ & & $\mathrm{N}$ & \\
\hline \multirow[t]{2}{*}{ R-Square ${ }^{\mathrm{b}}$} & 0.196 & & 0.231 & & 0.274 & & 0.288 & \\
\hline & \multicolumn{8}{|c|}{ One-way fixed-month effect model } \\
\hline \multicolumn{9}{|l|}{ Sample size (n) } \\
\hline Heat Index & -0.303 & 0.004 & -0.198 & 0.060 & -0.370 & 0.001 & -0.516 & $<0.0001$ \\
\hline Precipitation $(0.1 \mathrm{~mm})$ & & & -0.007 & $<0.0001$ & -0.012 & $<0.0001$ & -0.012 & $<0.0001$ \\
\hline Sunshine hours (hrs) & & & & & -0.138 & $<0.0001$ & -0.123 & $<0.0001$ \\
\hline Pressure $(\mathrm{kPa})$ & & & & & & & 0.856 & 0.002 \\
\hline Fixed time effect (Month) & $\mathrm{Y}$ & & $\mathrm{Y}$ & & $\mathrm{Y}$ & & $\mathrm{Y}$ & \\
\hline R-Square & 0.313 & & 0.340 & & 0.382 & & 0.392 & \\
\hline
\end{tabular}

a: Beta: Regression coefficient. B: R-Square: Coefficient of determination. 


\subsection{Ecological Association between Annual Average AQI and Total Mortality}

Of 161 cities with AQI data, we are able to collect reliable total mortality data from 110 cities in 2014. Annual average AQI concentrations were positively and significantly correlated with total mortality $\left(\mathrm{r}=0.2, \mathrm{R}^{2}=4.0 \%, \mathrm{p}=0.034\right)$. After adjustment for socioeconomic status (assessed by gross domestic product), the association between AQI and total mortality in 2014 remained statistically significant $\left(\mathrm{r}=0.21, \mathrm{R}^{2}=4.4 \%, \mathrm{p}=0.036\right)$.

\section{Discussion}

The main findings of the study highlight that (1) the highest average AQI was in winter, and the lowest in summer in 2014. Significant clustering distributions of cities with high AQI was observed by regions, with the highest AQI in North China, and lowest in Southwest China. (2) Changes in AQI concentrations were significantly correlated with changes in climate factors. (3) A positive and significant association between AQI and total mortality was observed.

\subsection{Burden of Air Pollution in China}

China is facing a great challenge of controlling air pollution, especially in urban cities and certain regions because of their great differences in geo-physical and socioeconomic environmental status. Our study shows that about more than one third $(32 \%-39 \%)$ of the study cities had AQI $\geq 100$ (classified as slightly polluted) in seven months of 2014 (Jan-March, May and Oct.-Dec.), and significantly higher proportions of cities had AQI $\geq 150$ (classified as moderately polluted) in Jan (41.61\%), Feb (16.15\%), Nov (7.45\%), and Dec (6.83), respectively. The variations in AQI were significantly and spatially clustered across the country. Overall, North and Northwest China had higher AQI than the rest of the country. Although several individual studies examined the differences in air quality across the cities, the present analysis is one of the first to use a larger sample size (161 cities) to test the geographic differences in AQI across the county. In Huang and his colleagues' study, they examined air pollution (assessed by PM2.5) from 13 air-monitoring stations in the city in 2013-2014 in Xi'an City, Shannxi province of China, and observed a significant clustering distribution of neighborhoods with elevated PM2.5 concentration across the 13 air-monitoring stations [25]. Kai et al. evaluated air quality in Guangzhou (located in south central China), compared with additional 11 large cities of China. They used air quality data monitored from 2000 to 2005. Their findings suggested that the average air quality in Guangzhou over 6 years was higher than that in Beijing, Tianjin, Nanjing, Hangzhou and Shanghai, and lower than that in Shenzhen, Zhuhai and Shantou [26]. Findings of our present study added new evidence by using a much larger sample size and applying more vigorous analysis to the body of the research literature and highlighted a serious variation in the burden of air pollution across the country. 


\subsection{Climate Change and AQI}

Climate change can be caused in part by increased atmospheric concentrations of carbon dioxide and other green-house gases. It is likely to result in changes in temperature, humidity, amount, distribution, and intensity of precipitation events and the intensity and frequency of certain extreme weather events [27]. In our study, significant and negative associations of AQI with heat index, precipitation, and positive association with atmospheric pressure were observed. A higher concentration of AQI in winter and lower concentration in summer has also been reported by other studies in China. For example, the concentration of PM2.5 was higher in winter and spring, but lower in summer reported in previous studies in Xi'an and Guangzhou cities of China [25] [26]. We confirmed this seasonal difference by using data across the country. We further examined the correlation between AQI and four major climate factors using panel fixed effect model (fixed for yearly-month effect), and panel pooled model (without fixed yearly-month effect). It suggests that on average, heat index was negatively correlated with AQI in China. A significant variation in air quality by seasons may be attributable to the natural climate changes, (such as cold months but less wind in winter, and lots of rainfall in summer), and use of different types for heating. In winter, coal is the main source of heating in most cities of China, which is considered the main factor for a poor air quality in cold months. A dry and dusty spring may account for a relatively higher concentration of air pollutants in spring. While in summer, there is lots of rainy and windy days, which can increase the sedimentation ability of the air and help the diffusion of air pollutants. In fall, a relatively low temperatures and winds are very common, both are not beneficial for the diffusion of air pollutants [24] [25]. Furthermore, cities in North China have experienced a longer history of industrialization as compared to South China. It consumes much more energy from coal or other sources than South China, which may be partly attributable to a higher concentration of air pollutants in the North versus the South. Although we are unable to examine details of the complex associations of air pollution with climate and energy use because of the lack of the data availability, findings from our study add to new evidence of the overall association between air quality and climate change and calls for more detail studies.

\subsection{Impact of Air Pollution on Population Health}

The association between air pollution and public health has been examined in several Chinese cities. These studies have found a positive association of air pollution with years of potential life lost, mortality, cardiovascular disease and respiratory diseases mortalities [4] [6] [7] [17] [24] [28] [29] [30]. The importance of controlled air pollution in urban cities was highlighted, although the data used for these studies were either local or from only a few major cities. For example, one of the previous studies found the significant association between ambient air population and adult respiratory mortality. Their data was from 32 
Chinese cities [24]. Our study has an advantage that utilized data from multiple sources released by the Chinese national air quality and health surveillance systems and was able to test for and confirm a significant and positive association between AQI and all-cause mortality. This finding further addresses the serious impact of air quality on urban public health.

There are several limitations that should be kept in mind when interpreting the major findings of this study. First, the associations between AQI and climate factors were analyzed cross-sectionally. It is not necessary to interpret as a cause-effect association, although changes in regional distribution of temperature show that a warming trend was more significant in West, East and North China than in South China [6]. Second, data for the analysis of the association between AQI and meteorological factors were only available in 50 cities of the 161 , which reduced the statistical power when we tested the association between AQI and mortality with adjustment for climate factors (data not shown). Third, more detail health related data at individual city levels were not available. Therefore, further studies with multiple-sits and multiple disciplinary collaboration are needed. Nevertheless, the present study also has several advantages. First, as compared to all previous publications, the present study had the largest sample size on air quality which was measured in 161 major cities, almost half of the total cities of China. Second, the accuracy and quality of data on AQI, meteorological and health outcomes are reliable as they were consistent and reported by Chinese authority agencies, which offer a comparable base for further studies. Third, using the spatial autocorrelation technique, the present study is able to quantitatively test and confirm a spatial clustering of AQI across the regions of China. The panel fixed analysis is one of the first to address the collection between AQI and meteorological factors by fixed-months effect (differences in temperature across the regions by months). The study provides further evidence to public health policy makers on air quality control and health outcomes promotion.

In conclusion, findings of this study indicate that the burden of air pollution remains a serious public health issue. AQI significantly varies across the country, and is significantly associated with climate factors, and is positively and significantly associated with total mortality.

\section{Acknowledgements}

The Drexel-SARI Co-Research and Education on Low Carbon and Healthy City Technology (LCHCT) Study is support by a joint grant (\#282582) of Drexel University Office of International Programs and Shanghai Advanced Research Institute (SARI) of the Chinese Academy of Science. The Drexel-SARI LCHCL Study has provided numerous opportunities of research and training to our under- and graduate students for their practicum, research thesis and research practice in summer internships (2014 and 2016), and as well as to our collaborators and visiting scholars from China. Our specific thanks go to those who as- 
sisted data collection and preliminary data analysis in the past years: Drexel SPH MPH2014: Xuehui Qian, Purva Jian; SPH MS2015: Hui Liu, Xuan Yang, Jessica Dow, Ruby Sung; SPH MPH2015: Lili Lin, Xuan Yang, Xiaochen Zhang, and Mingfei Zhao. Kathleen Ross, Emily Valencia; SPH MS2016: Haoyang Guo; SPH MPH: Jinggaofu Shi; Drexel SPH MPH2017: Bingqing Zhang, Siyu Li; Drexel SBESHS MS2017: Chiranjiv Chevli, and Drexel COAS BS2017: Feng Jia and Baihui Huang. Our Specific thanks also go to Professor Julie Mostov, the former Senior Vice-Provost for Global Initiatives at Drexel University (now, the Dean of New York University for Liberal Studies), and to Miss Heidi West, the former Director of Drexel Office of International Programs (now, the Director of Programs and Operations, Global Environmental Health Lab, NY), and Mr. Adam Zahn, the Associate Director of Drexel Office of International Programs for their excellent and continued support for the study.

\section{Conflict of Interest}

None.

\section{References}

[1] Wikipedia China: Urbanization in China. 6 March, 2017. https://en.wikipedia.org/wiki/Urbanization_in_China

[2] Li, L., Qian, J., Ou, C.-Q., Zhou, Y.-X., Guo, C. and Guo, Y. (2014) Spatial and Temporal Analysis of Air Pollution Index and Its Timescale-Dependent Relationship with Meteorological Factors in Guangzhou, China, 2001-2011. Environmental Pollution, 190, 75-81. https://doi.org/10.1016/j.envpol.2014.03.020

[3] Kan, H., Chen, B. and Hong, C. (2009) Health Impact of Outdoor Air Pollution in China: Current Knowledge and Future Research Needs. Environ Health Perspect, 117, A187. https://doi.org/10.1289/ehp.12737

[4] Guo, Y., Li, S., Tian, Z., Pan, X., Zhang, J. and Williams, G. (2013) The Burden of Air Pollution on Years of Life Lost in Beijing, China, 2004-08: Retrospective Regression Analysis of Daily Deaths. BMJ (Clinical Research ed), 347, f7139. https://doi.org/10.1136/bmj.f7139

[5] Yao, L. and Lu. N. (2014) Spatiotemporal Distribution and Short-Term Trends of Particulate Matter Concentration over China, 2006-2010. Environ Sci Pollut Res Int, 21, 9665-9675. https://doi.org/10.1007/s11356-014-2996-3

[6] Kan, H., Chen, R. and Tong, S. (2012) Ambient Air Pollution, Climate Change, and Population Health in China. Environ Int, 42, 10-19. https://doi.org/10.1016/j.envint.2011.03.003

[7] Wong, C.M., Vichit-Vadakan, N., Vajanapoom, N., Ostro, B., Thach, T.Q., Chau, P.Y., et al. (2010) Part 5. Public Health and Air Pollution in Asia (PAPA): A Combined Analysis of Four Studies of Air Pollution and Mortality. Res Rep Health Eff Inst, (154):377-418.

[8] Johansson, C., Norman, M. and Gidhagen, L. (2007) Spatial \& Temporal Variations of PM10 and Particle Number Concentrations in Urban Air. Environ Monit Assess, 127, 477-487. https://doi.org/10.1007/s10661-006-9296-4

[9] Karar, K., Gupta, A., Kumar, A. and Biswas, A.K. (2006) Seasonal Variations of PM10 and TSP in Residential and Industrial Sites in an Urban Area of Kolkata, In- 
dia. Environ Monit Assess, 118, 369-381. https://doi.org/10.1007/s10661-006-1503-9

[10] Gupta, A., Karar, K., Ayoob, S. and John, K. (2008) Spatio-Temporal Characteristics of Gaseous and Particulate Pollutants in an Urban Region of Kolkata, India. Atmospheric Research, 87, 103-115. https://doi.org/10.1016/j.atmosres.2007.07.008

[11] Rooney, M.S., Arku, R.E., Dionisio, K.L., Paciorek, C., Friedman, A.B., Carmichael, H., Zhou, Z., Hughes, A.F., Vallarino, J. and Agyei-Mensah, S. (2012) Spatial and Temporal Patterns of Particulate Matter Sources and Pollution in Four Communities in Accra, Ghana. Sci Total Environ, 435, 107-114. https://doi.org/10.1016/j.scitotenv.2012.06.077

[12] Liu, L., Yang, X., Liu, H., Wang, M., Welles, S., Márquez, S., Frank, A. and Haas, C.N. (2016) Spatial-Temporal Analysis of Air Pollution, Climate Change, and Total Mortality in 120 Cities of China, 2012-2013. Frontiers in Public Health, 4.

[13] China Ministry of Environmental Protection: Daily Air Quality Report in Cities of China. 1 June-15 November, 2014. http://datacenter.mep.gov.cn/websjzx/queryIndex.vm

[14] China Meteorology Center. China Meteorological Data Sharing Service System. 1 August-16 November, 2014. http://cdc.nmic.cn/home.do

[15] National Bureau of Statistics of China: National Data. 1 June-16 November, 2016. http://data.stats.gov.cn/index.htm

[16] China CDC: Data for National Health Statistics. 16 July, 2015. http://www.chinacdc.cn/tjsj_6693/

[17] Wong, C.-M., Ma, S., Hedley, A.J. and Lam, T.-H. (2001) Effect of Air Pollution on Daily Mortality in Hong Kong. Environ Health Perspect, 109, 335. https://doi.org/10.1289/ehp.01109335

[18] China Meteorological Data Service Center: The Meteorological Data Sharing Network. http://data.cma.cn/en

[19] Rothfusz, L.P. (1990) The Heat Index Equation. National Weather Service Technical Attachment (SR 90-23).

[20] Wikipedia - China: List of Regions of the People's Republic of China. 1 September, 2015.

https://en.wikipedia.org/wiki/List_of_regions_of_the_People\%27s_Republic_of_Chi na

[21] GIS:Arc Geographic Information System. 1 June-16 September, 2015. http://www.esri.com/

[22] SAS, Institute: Base SAS 9.4 Procedures Guide: Statistical Procedures. Oct 6, 2017. http://support.sas.com/documentation/onlinedoc/base/procstat $93 \mathrm{~m} 1 . p d f$

[23] Wikipedia - PA: Panel Analysis. 6 September, 2015. https://en.wikipedia.org/wiki/Panel_analysis

[24] Zhou, M., He, G., Liu, Y., Yin, P., Li, Y., Kan, H., Fan, M., Xue, A. and Fan, M. (2015) The Associations between Ambient Air Pollution and Adult Respiratory Mortality in 32 Major Chinese Cities, 2006-2010. Environ Res, 137, 278-286. https://doi.org/10.1016/j.envres.2014.12.016

[25] Huang, P., Zhang, J., Tang, Y. and Liu, L. (2015) Spatial and Temporal Distribution of PM2. 5 Pollution in Xi'an City, China. Int J Environ Res Public Health, 12, 6608-6625. https://doi.org/10.3390/ijerph120606608

[26] Kai, Z., Ye, Y.-H., Qiang, L., Liu, A.-J. and Peng, S.-L. (2007) Evaluation of Ambient Air Quality in Guangzhou, China. Journal of Environmental Sciences, 19, 432-437. https://doi.org/10.1016/S1001-0742(07)60072-2 
[27] Reid, C.E. and Gamble, J.L. (2009) Aeroallergens, Allergic Disease, and Climate Change: Impacts and Adaptation. Ecohealth, 6, 458-470.

https://doi.org/10.1007/s10393-009-0261-X

[28] Chen, R., Kan, H., Chen, B., Huang, W., Bai, Z., Song, G. and Pan, G. (2012) Association of Particulate Air Pollution with Daily Mortality: The China Air Pollution and Health Effects Study. Am J Epidemiol, 175, 1173-1181.

https://doi.org/10.1093/aje/kwr425

[29] Qian, Z., Lin, H.-M., Stewart, W.F., Kong, L., Xu, F., Zhou, D., Zhu, Z., Liang, S., Chen, W. and Shah, N. (2010) Seasonal Pattern of the Acute Mortality Effects of Air Pollution. J Air Waste Manag Assoc, 60, 481-488.

https://doi.org/10.3155/1047-3289.60.4.481

[30] Matus, K., Nam, K.-M., Selin, N.E., Lamsal, L.N., Reilly, J.M. and Paltsev, S. (2012) Health Damages from Air Pollution in China. Global Environmental Change, 22, 55-66. https://doi.org/10.1016/j.gloenvcha.2011.08.006 